\title{
Itch and Analgesia Resulting from Intrathecal Application of Morphine: Contrasting Effects on Different Populations of Trigeminothalamic Tract Neurons
}

\author{
Hannah R. Moser and Glenn J. Giesler, Jr. \\ Graduate Program in Neuroscience and Department of Neuroscience, University of Minnesota, Minneapolis, Minnesota, 55455
}

\begin{abstract}
Intrathecal application of morphine is among the most powerful methods used to treat severe chronic pain. However, this approach commonly produces itch sufficiently severe that patients are forced to choose between relief of pain or itch. The neuronal populations responsible for processing and transmitting information underlying itch caused by intrathecal application of morphine have not been identified and characterized. We describe two populations of antidromically identified trigeminothalamic tract (VTT) neurons in anesthetized rats that are differentially affected by morphine and explain several aspects of opioid-induced itch and analgesia. We found that intrathecal application of morphine increased ongoing activity of itch-responsive VTT neurons. In addition, intrathecal application of morphine increased responses to pruritogens injected into the skin and greatly heightened responses to innocuous mechanical stimuli. In contrast, the ongoing activity and responses to noxious pinches in nociceptive VTT neurons were frequently inhibited by the same dose of morphine. These results reveal that i.t. application of morphine affects specific subpopulations of VTT neurons in ways that may produce itch, hyperknesis, alloknesis, and analgesia.
\end{abstract}

\section{Introduction}

Morphine remains one of the most commonly prescribed drugs for treatment of severe chronic pain, and intrathecal application of morphine is one of the most powerful treatments available for patients. However side effects, including itch, can limit the maximum tolerable dose, and thus the effectiveness of morphine for producing analgesia. The incidence of opioid-induced pruritus is especially high (20-100\%) following intrathecal administration (Baraka et al., 1982; Bromage et al., 1982; Ballantyne et al., 1988; Szarvas et al., 2003; Ganesh and Maxwell, 2007). Itch can be accompanied by debilitating phenomena such as hyperknesis, increased itch caused by pruritogens, and alloknesis, itch caused by innocuous mechanical stimuli that normally do not cause itch. Opioids likely play a role in producing both; morphine administration causes hyperknesis (Fjellner and Hägermark, 1982; Onigbogi et al., 2000), and opioid receptor antagonists reduce alloknesis (Heyer et al., 2002). Endogenous opioids are likely involved in producing pruritus associated with atopic dermatitis, chronic urticaria, or cholestasis, as itch accompanying these conditions is treated with opioid receptor antagonists (Phan et al., 2010).

Received Jan. 16, 2013; revised Feb. 22, 2013; accepted Feb. 23, 2013

Author contributions: H.R.M. and G.J.G. designed research; H.R.M. performed research; H.R.M. analyzed data; H.R.M. and G.J.G. wrote the paper.

This work was supported by National Institutes of Health grants to G.J.G. (NS047399) and H.R.M. (NS077554). We thank H. Truong for valuable technical assistance and B. Lipshetz for help in some experiments. We also thank Dr. V. Seybold, Dr. D. Simone, B. Lipshetz, and J. Giesler for critically reading this manuscript.

The authors declare no competing financial interests.

Correspondence should be addressed to Glenn J. Giesler, Jr., Department of Neuroscience, University of Minnesota, 6-145 Jackson Hall, 321 Church Street SE, Minneapolis, MN 55455. E-mail: Giesler@umn.edu.

DOI:10.1523/JNEUROSCI.0216-13.2013

Copyright $\odot 2013$ the authors $\quad 0270-6474 / 13 / 336093-09 \$ 15.00 / 0$
Surprisingly, pruritus caused by intrathecal application of morphine is often localized to facial regions of patients (Scott et al., 1980; Baraka et al., 1981; Collier, 1981; Bromage et al., 1982), suggesting the value of using animal models of facial itch to study this phenomenon. Pruritogens and algogens produce distinct behavioral responses when applied to the face of mice (Shimada and LaMotte, 2008) or rats (Klein et al., 2011), indicating that sensory neurons receiving input from rodent facial skin are valuable for investigating mechanisms of itch and pain. Spradley et al. (2012) showed that itch-related facial scratching is reduced by $\mu$-opioid receptor antagonists while pain-related wiping is reduced by morphine, suggesting that $\mu$-opioid receptor activation has opposite effects on itch versus pain signaling related to the face. In addition, intracisternal injection of morphine causes robust body and facial scratching in rats (Koenigstein, 1948; Lee et al., 2003) as does injection of morphine within the spinal trigeminal nucleus (Thomas and Hammond, 1995). Thus, the rat trigeminal system appears to be valuable for studies of the mechanisms underlying morphine-induced itch.

We (Moser and Giesler, 2011) examined the responses of trigeminothalamic tract (VTT) neurons of rats to facial application of algogens and pruritogens. Approximately two-thirds of such neurons were powerfully activated by intradermal injections of pruritogens such as chloroquine, histamine, and serotonin into the face. Serotonin evokes robust itch responses in rats (Berendsen and Broekkamp, 1991; Thomsen et al., 2001; Klein et al., 2011) and humans (Weisshaar et al., 1997; Thomsen et al., 2002; Hosogi et al., 2006; Rasul et al., 2012) and it is elevated within the skin in various human dermatologic diseases that produce itch (Lundeberg et al., 1999; Soga et al., 2007).

Here, we examined the effects of intrathecal application of morphine on rat VTT neurons. Our findings indicate that mor- 
phine often inhibits nociceptive VTT neurons but activates pruriceptive VTT neurons and increases their responses to pruriceptive and innocuous mechanical inputs. The activation and increased evoked responses of pruriceptive VTT neurons likely contribute to itch, hyperknesis, and alloknesis.

\section{Materials and Methods}

Adult male Sprague Dawley rats (300-450 g) were used according to protocols approved by the Institutional Animal Care and Use Committee at the University of Minnesota. Animals were deeply anesthetized with urethane (1.5 mg/kg, i.p.; Sigma) and tracheostomized. An intravenous catheter was placed in the left jugular vein for intravenous injections. A laminectomy was performed over the first cervical segment (C1) to allow recording of neurons with receptive fields on the face below the eye and caudal to the vibrissal pad, an area corresponding to that in which pruritogens were applied in behavioral studies (Shimada and LaMotte, 2008; Klein et al., 2011). A craniotomy was performed over the right thalamus. The dura was removed from brain and spinal cord. A low-impedance stainless steel electrode was positioned at stereotaxic coordinates for the ventroposterior medial (VPM) nucleus in the thalamus. Pulses of electrical current (300-500 $\mu \mathrm{A}, 200 \mu \mathrm{s}, 3 \mathrm{~Hz})$ were delivered through the electrode as an initial search stimulus. A stainless steel recording electrode (10 M $\Omega$; FHC) was lowered through the dorsal horn of the contralateral caudal medulla and $\mathrm{C} 1$ to search for time-locked single unit responses, which met the following criteria for antidromically activated VTT neurons: (1) stable response latency ( $<0.05$ ms variation), (2) ability to follow stimulus trains of $\geq 300 \mathrm{~Hz}$, and (3) collision of orthodromic spikes with putative antidromic responses. Single-unit responses that met these criteria and had cutaneous facial receptive fields located caudal to the vibrissal pad were used for further study. Action potentials were amplified, filtered, and digitized and waveform discriminated using DAPSYS data acquisition processor system software (www.dapsys.net).

Axon projection mapping. The amount of current required to elicit an antidromic spike was determined at $200 \mu \mathrm{m}$ intervals throughout vertical stimulating tracks separated by mediolateral and rostrocaudal intervals of $300-500 \mu \mathrm{m}$. The point at which the threshold for antidromic activation was lowest $(\leq 30 \mu \mathrm{A})$ was assumed to be the most accurate indication of the position of the axon terminal (Burstein et al., 1991; Dado et al., 1994). If the antidromic latency did not change at any more rostral position, it was assumed that the axon did not extend rostrally beyond the identified low threshold point.

Characterization of neurons with mechanical and chemical stimuli. Innocuous brushing with a soft-bristled brush and the minimum necessary amount of noxious stimuli were used to identify the mechanical receptive field boundaries for each antidromically identified VTT neuron. Brushing and pressure and pinch applied with small clips were used to classify each neuron as high threshold (HT; responsive only to noxious pinching), wide dynamic range (WDR; responsive to brushing with higher discharge rate in response to pressure and pinching), or low threshold (maximally responsive to innocuous brushing).

Each cell was characterized using the following established pruritogens in rodents (Klein et al., 2011; Wilson et al., 2011): histamine dihydrochloride ( $600 \mathrm{~mm}$; Sigma), serotonin creatinine sulfate complex ( $47 \mathrm{~mm}$; Sigma), chloroquine diphosphate salt (100 mm; Sigma), and/or bovine adrenal medullary 8-22 peptide (BAM8-22, 1 mM; Tocris Bioscience). Each drug was injected intradermally in a $10 \mu$ l volume within the mechanical receptive field; every effort was made to use sites separated by $>5 \mathrm{~mm}$ whenever possible. The effects of injection of $\mathrm{pH}$-matched $0.9 \%$ normal saline vehicle were always determined before an active stimulus. Drugs were injected in random order on each trial, with a minimum of 5 min between drug injections. If a cell responded to a pruritogen, no other pruritogen was applied and the effects of morphine were determined.

Morphine sulfate (100 ng in $500 \mu \mathrm{l}$; Sigma) or vehicle was applied to the surface of the spinal cord using a syringe and polyethylene tubing. Agar was used to build a dam enclosing the caudal medulla and the first and second cervical spinal cord segments. When testing effects of morphine on subsequently applied stimuli, the second stimulus (serotonin, intradermal or brush/pinch) was applied $\geq 15$ min after intrathecal ap- plication of vehicle or morphine. Naloxone hydrochloride $(1 \mathrm{mg} / \mathrm{kg}$; Tocris Bioscience) was delivered via intravenous catheter.

Histology. At the end of each experiment, low-threshold antidromic stimulation site(s) in the thalamus and recording site(s) were marked with electrolytic lesions. Rats were perfused with $0.9 \%$ normal saline followed by $10 \%$ formalin with $1 \%$ ferrocyanide (for Prussian blue reaction at lesion sites). The brain, including thalamus, medulla, and rostral cervical spinal cord, was removed and sectioned $(50-75 \mu \mathrm{m})$ on a freezing microtome and stained with neutral red. A rat brain atlas (Paxinos and Watson, 1982) was used to identify thalamic nuclei.

Data analysis. A cell was considered responsive to a stimulus if it exhibited a change in mean ongoing discharge rate of $\pm 50 \%$ after stimulus application, with a longer duration than any change due to vehicle. For all analyses, discharge rates were normalized to $60 \mathrm{~s}$ of baseline activity before treatment. For effects on ongoing activity, mean responses to vehicle, morphine, or naloxone were measured during a $3 \mathrm{~min}$ period beginning $1 \mathrm{~min}$ after stimulus application. For effects on subsequent applications of pruritogen, the mean response to serotonin was measured over the $5 \mathrm{~min}$ period following injection of the pruritogen. To examine effects of morphine on responses to mechanical stimuli, mean responses to brush or pinch were calculated over the $10 \mathrm{~s}$ of brush or pinch application. Histograms are reported in $1 \mathrm{~s}$ bins, unless otherwise noted. All error bars indicate SEM. Wilcoxon rank sums or KruskalWallis ANOVA analyses with Dunn's post-test were used to compare effects across treatments, with $p<0.05$ considered significant.

\section{Results}

The effects of morphine were tested on two populations of antidromically identified nociceptive VTT neurons located within the caudal medulla and C1 spinal segment: pruriceptive cells and nociceptive (nonpruriceptive) cells. Pruriceptive cells responded to noxious stimulation and to at least one pruritogen. Nociceptive cells responded to noxious stimulation but not to any tested pruritogens.

\section{Effects of intrathecal application of morphine on ongoing activity}

The intrathecal application of morphine excited pruriceptive cells and inhibited nociceptive cells. An example of the effects of intrathecal application of morphine on a pruriceptive VTT neuron is shown in Figure 1. This cell was recorded in the superficial dorsal horn $(\mathrm{sDH})$ (Fig. $1 A$ ) and had a receptive field located below the eye and caudal to the vibrissal pad (Fig. 1B). The cell was activated by high-frequency stimulus trains with stable antidromic latencies, and orthodromic action potentials collided with antidromic spikes (Fig. $1 C$ ). Its axon terminated in the contralateral VPM nucleus in the thalamus (Fig. 1D). This VTT neuron responded to innocuous and noxious mechanical stimuli (Fig. $1 E$ ) as well as to intradermal injection of serotonin (Fig. $1 F$ ), and was therefore classified as a pruriceptive VTT neuron. Vehicle applied to the cord had no effect on the ongoing response of the cell to serotonin. However, intrathecal application of morphine resulted in a pronounced increase in ongoing discharge, which lasted $>5 \mathrm{~min}$. The mean discharge rate during morphine application reached a level that exceeded its response to the pruritogen by greater than fourfold. Intravenous injection of naloxone reduced activity to the level seen before morphine application (Fig. $1 F$ ), indicating that the effect was likely mediated via opioid receptors.

An example of the contrasting responses of nociceptive VTT neurons to intrathecal application of morphine is illustrated in Figure 2. This cell was recorded within the sDH of the caudal medulla (Fig. 2A) and projected to the contralateral VPM nucleus in the thalamus (Fig. 2C). This neuron responded to innocuous and noxious mechanical stimulation of the receptive field (Fig. 

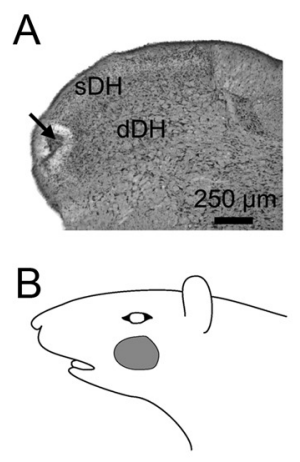

F

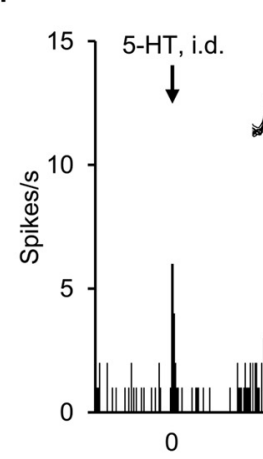

0
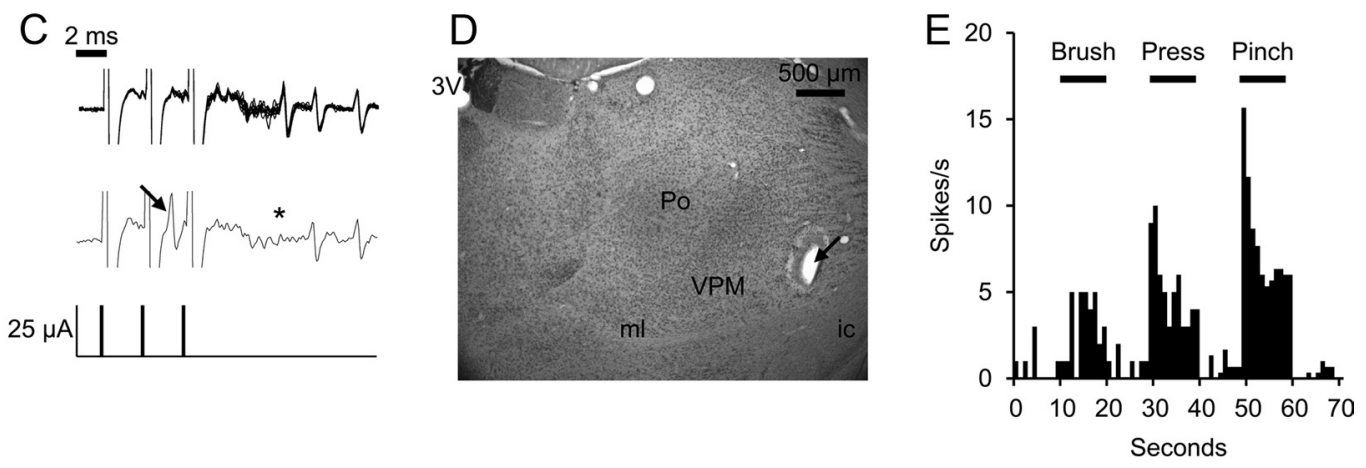

Figure 1. Example of activation of a pruriceptive VTT neuron by intrathecal (i.t.) application of morphine. $\boldsymbol{A}$, Lesion at the recording point (arrow) in sDH of C1 segment. $\boldsymbol{B}$, Receptive field. $\boldsymbol{C}$, Ten overlaid spike traces exhibit ability to follow high-frequency stimulus train with a fixed latency (11.4 ms) between antidromic stimulation ( $25 \mu \mathrm{A}$ ) and recorded spike (top), and collision of orthodromic spike (arrow) with antidromic spike (asterisk at expected latency) (bottom). D, Lesion at the stimulation point (arrow) in the thalamus. 3V, third ventricle; P0, posterior nucleus; ml, medial lemniscus; ic, internal capsule. $\boldsymbol{E}$, Responses to brush, pressure, and pinch. $\boldsymbol{F}$, Response to intradermal (i.d.) injection of serotonin (5-HT) into the receptive field, i.t. application of vehicle and morphine, and intravenous injection of naloxone. Onset of i.d. and i.v. injections denoted by arrows; onset of i.t. application denoted by dotted line, with duration denoted by shading. Insets, Ten overlaid consecutive spike traces, beginning at arrow.
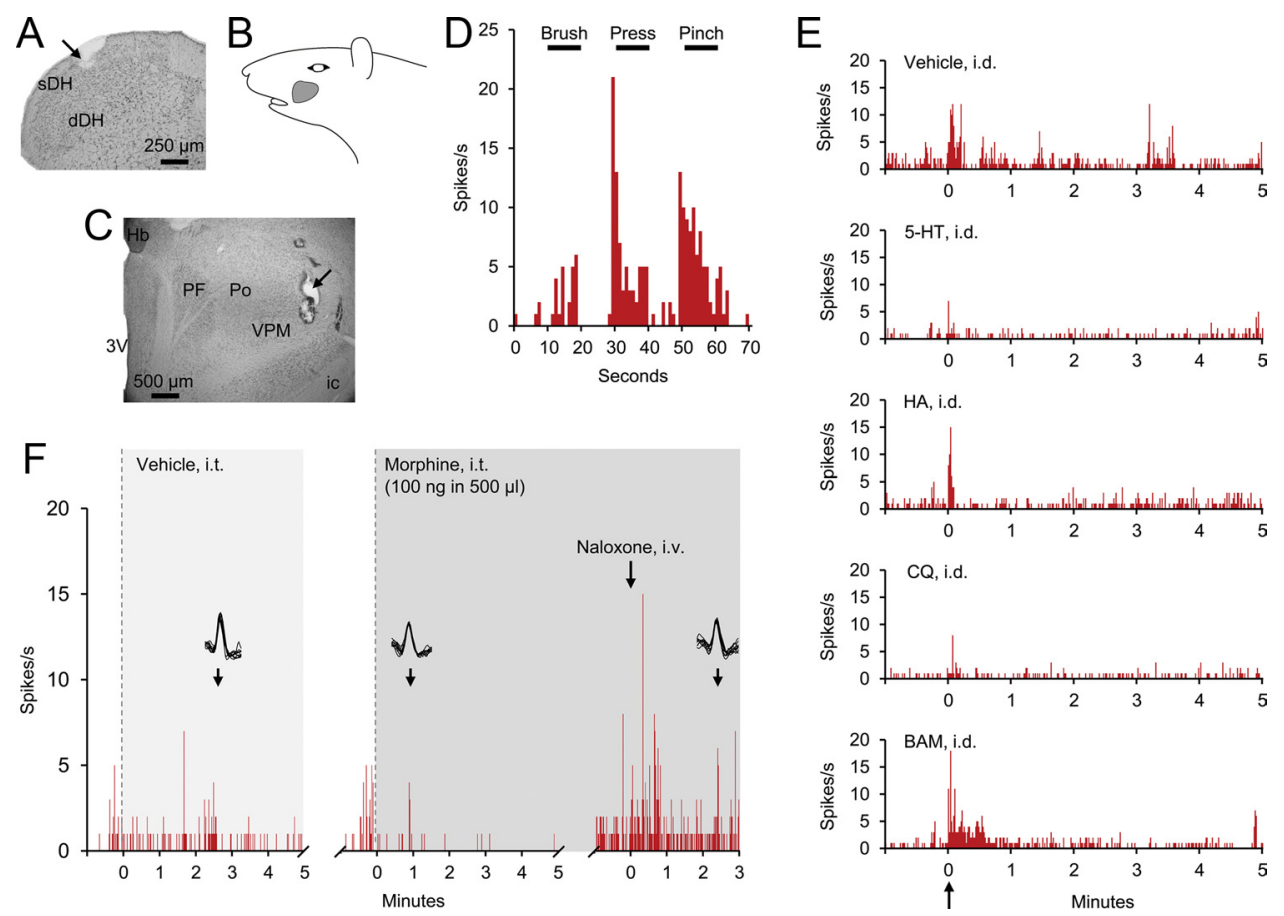

Figure 2. Example of inhibition of a nociceptive (nonpruriceptive) VTT neuron by intrathecal (i.t.) application of morphine. $\boldsymbol{A}$, Lesion at the recording point (arrow) in the sDH of caudal medulla. $\boldsymbol{B}$, Receptive field. $\boldsymbol{C}$, Lesion at the stimulation point (arrow) in thalamus. Hb, habenular nucleus; PF, parafascicular nucleus, others are as in Fig. 1.D, Responses to brush, pressure, and pinch. $\boldsymbol{E}$, Firing levels following intradermal (i.d.) injections of vehicle, serotonin, histamine (HA), chloroquine (CQ), and BAM8-22 (BAM) into the receptive field. $\boldsymbol{F}$, Responses during i.t. application of vehicle and morphine, and intravenous injection of naloxone. 
$2 B, D)$ but not to any of the four tested pruritogens (Fig. 2E). Application of vehicle to the spinal cord had no effect, whereas the same dose of intrathecally applied morphine resulted in a reduction in discharge rate, which was reversed by naloxone (Fig. $2 F$ ); administration of naloxone often resulted in an increase in activity to a higher level than observed before morphine application, a phenomenon that has been noted in several past studies (Le Bars et al., 1975, 1976; Henry, 1979; Lombard and Besson, 1989; Jones et al., 1990).

The mean responses of pruriceptive and nociceptive VTT neurons to intrathecal application of morphine are illustrated in Figure 3. In pruriceptive VTT neurons, including cells responsive to serotonin $(n=7)$, histamine $(n=3)$, and chloroquine $(n=1)$, morphine significantly increased the mean firing level in response to the pruritogen by more than twofold (Fig. $3 A, B ; p=0.008$ ). Seven of the 11 tested pruriceptive VTT neurons met our criteria for activation. None of the pruriceptive neurons were inhibited by intrathecal application of morphine (Fig. 3C). Activity in none of the pruriceptive VTT neurons was significantly affected by intravenous injection of $100 \mathrm{ng}$ of morphine (Fig. $3 B$ ), indicating that the same dose given intrathecally has a spinal site of action. In contrast, intrathecal application of morphine significantly decreased ongoing discharge rate in nociceptive VTT neurons (Fig. $3 D, E ; p=0.02$ ). None of the nociceptive neurons were excited by morphine (Fig. $3 F$ ). As was the case with pruriceptive VTT neurons, intravenous injection of $100 \mathrm{ng}$ of morphine had no significant effect on the firing of nociceptive VTT neurons (Fig. 3D). In all cases, the effect of morphine was reversed with intravenous injection of naloxone.

Four pruriceptive VTT neurons were classified as HT and seven as WDR. Five nociceptive VTT neurons were classified as HT and six as WDR. Seven pruriceptive VTT neurons were recorded in the sDH and four in the deep dorsal horn $(\mathrm{dDH})$. Six nociceptive VTT neurons were recorded in the sDH and 5 in the $\mathrm{dDH}$. Six pruriceptive VTT neurons projected to the VPM nucleus, two to the posterior thalamus, and two to the ventral lateral geniculate nucleus; the axon location was not recovered for one pruriceptive VTT neuron. Seven nociceptive VTT neurons projected to the VPM nucleus, two to the posterior thalamus, and one to the medial geniculate nucleus; the axon location was not recovered for one nociceptive VTT neuron (data not shown). In summary, there were no distinct differences noted in response classification (HT vs WDR), cell body position, or thalamic axon location for pruriceptive and nociceptive VTT neurons.

Effects of intrathecal application of morphine on subsequent responses to pruritogens

Morphine can cause hyperknesis in humans (Fjellner and Hägermark, 1982) and rats (Onigbogi et al., 2000). Figure $4 A$ illustrates an example of a neuron in which the pruritogen sero- tonin was injected intradermally before and then repeated a second time after intrathecal application of vehicle, and a third time after intrathecal application of morphine. In each of the four neurons tested, the response to intradermal injection of serotonin was reduced after intrathecal application of vehicle, although the mean response was not significantly different from baseline $(p=0.06)$. Intrathecal application of morphine increased the response to intradermal injection of serotonin in each of the four neurons. The magnitude of the response to intradermal injection of serotonin was significantly increased after intrathecal application of morphine compared with either the baseline response $(p=0.04)$ or to the response after intrathecal application of vehicle $(p=0.02)$ (Fig. $4 B$ ). These results suggest that morphine may cause hyperknesis by increasing responses of pruriceptive VTT neurons to pruritogens.

Effects of intrathecal application of morphine on responses to innocuous versus noxious mechanical stimuli

Opioids have also been implicated in the production of alloknesis (Heyer et al., 2002). We tested the effects of intrathecal application of morphine on responses evoked by innocuous brushing in pruriceptive and nociceptive VTT neurons and found that responses to brushing were increased by morphine in 8 of 10 pruriceptive VTT neurons. An example of a dramatically increased response of a pruriceptive VTT neuron to brushing during intrathecal application of morphine is illustrated in Figure 5A. Mean 

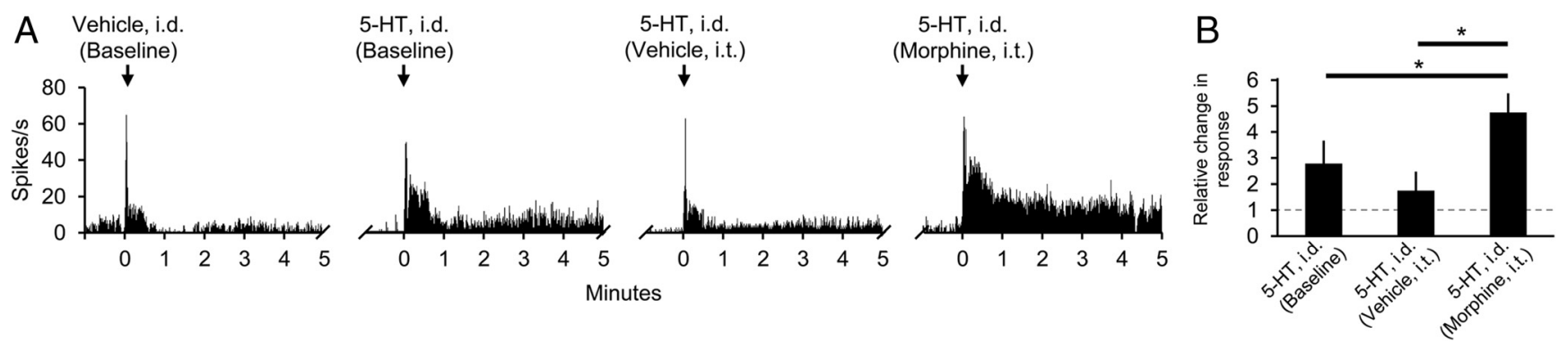

Figure 4. Effects of intrathecal (i.t.) application of morphine on responses to the pruritogen serotonin. $\boldsymbol{A}$, Example of responses of a single cell to intradermal (i.d.) injections of vehicle and serotonin into the receptive field under baseline conditions, to a second i.d. injection of serotonin $15 \mathrm{~min}$ after i.t. application of vehicle, and to a third i.d. injection of serotonin 15 min after i.t. application of morphine. $\boldsymbol{B}$, Effects of i.t. application of vehicle or morphine on mean response to subsequent application of serotonin $(n=4)$.
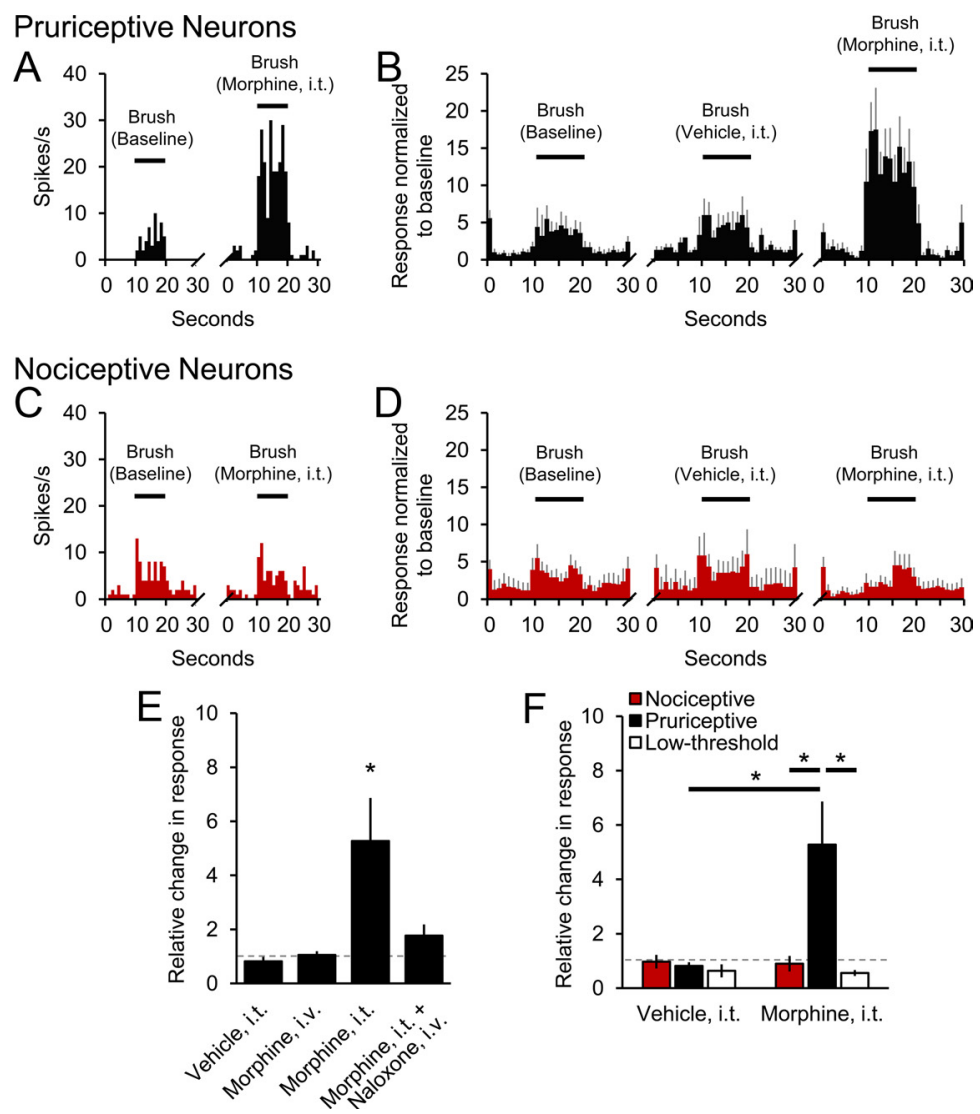

Figure 5. Differing effects of intrathecal (i.t.) application of morphine on responses to innocuous brushing. $\boldsymbol{A}$, Example of a pruriceptive VTT neuron's baseline response to brushing and greatly increased response in the presence of morphine. $\boldsymbol{B}$, Mean histograms of response of pruriceptive cells $(n=10)$ to brushing under three conditions. C, Example of a nociceptive VTT neuron's baseline response to brushing and similar response in the presence of morphine. $\boldsymbol{D}$, Mean histograms of response of nociceptive cells $(n=10)$ to brushing under three conditions. $E$, Normalized mean discharge rates during brushing for pruriceptive cells during four conditions. $F$, Effects of i.t. application of vehicle and morphine on normalized mean responses of nociceptive, pruriceptive, and low-threshold ( $n=5)$ VTT neurons to brushing.

responses of pruriceptive cells to brushing were increased fivefold in the presence of morphine (Fig. $5 B, E ; p=0.02$ ). These increases were reversed by naloxone (Fig. $5 E$ ). Neither intrathecal application of vehicle nor intravenous injection of morphine (100 ng) altered responses to brushing (Fig. 5E).

Unlike in pruriceptive cells, the mean response of nociceptive VTT neurons to brushing was not significantly affected by intrathecal application of morphine (Fig. $5 C, D, F$ ); the response to brushing was increased by morphine in only 1 of 10 nociceptive cells. In addition, intrathecal application of morphine had no effect on responses to brushing in nonpruriceptive cells that re- spond only to low-threshold stimuli (Fig. $5 F$ ). These results suggest that intrathecal application of morphine likely contributes to alloknesis by increasing responses to innocuous mechanical stimuli only in pruriceptive cells, that the actions are likely mediated by opioid receptors, and that the site of action is within the spinal cord.

We also examined the effects of intrathecal application of morphine on responses to noxious pinching in both pruriceptive and nociceptive VTT neurons. Morphine did not alter pinchevoked responses in pruriceptive cells; an example is shown in Figure 6A. The mean responses of all tested pruriceptive VTT neurons to pinching at baseline, in the presence of intrathecal vehicle and intrathecal morphine, are illustrated in Figure $6 B$; only 2 of 10 pruriceptive cells exhibited decreased responses to pinching during intrathecal application of morphine. In nociceptive VTT neurons, intrathecal application of morphine reduced responses to pinching by nearly $80 \%$ (Fig. $6 C, D ; p=0.04) ; 9$ of 10 nociceptive cells exhibited decreased responses to pinching during intrathecal application of morphine. This reduction was reversed by naloxone, and intravenous injection of morphine (100 ng) had no effect (Fig. 6E). Figure $6 F$ summarizes and compares the effects of morphine on pinch-evoked responses of pruriceptive and nociceptive cells. These results suggest that, although both types of VTT neurons are clearly activated by noxious pinching, intrathecal application of morphine at the dose used inhibits pinching responses only in nociceptive neurons. Reduced ongoing activity (Fig. 3C,D) and responses to noxious stimuli by nociceptive VTT neurons may contribute to analgesia resulting from intrathecal application of morphine.

\section{Discussion}

We have found that intrathecal application of morphine has dramatically different effects on pruriceptive and nociceptive VTT neurons. Pruriceptive signaling was increased by morphine. In 
some cases, intrathecal application of morphine increased by up to fourfold the ongoing discharge rates produced by intradermal injection of a pruritogen. If increased discharge rates in pruriceptive VTT neurons signal itch, then it would seem that the dramatically increased discharges caused by morphine should greatly increase the intensity of itch. In addition, responses to intradermal injection of the pruritogen serotonin following intrathecal application of morphine were increased, possibly contributing to hyperknesis, and responses to innocuous brushing were greatly increased, possibly contributing to alloknesis. None of the pruriceptive VTT neurons were inhibited by morphine. In contrast, intrathecal application of morphine inhibited ongoing activity and pinch-evoked responses in nociceptive VTT neurons without affecting responses to brushing. None were excited by morphine. The consistent nature of these effects, if confirmed, would suggest that excitation or inhibition resulting from intrathecal application of morphine alone could be sufficient to identify these two cell types in future studies. Together, these changes to discharge in both pruriceptive and nociceptive VTT neurons produced by intrathecal application of morphine would appear to act to increase itch and reduce pain sensations (Fig. 7).

There is a great deal of evidence supporting an inhibitory role for morphine on nociceptive spinal neurons, including projection neurons; supporting data have come from a variety of species, experimental preparations, and routes of administration (Satoh et al., 1971; Kitihata et al., 1974; Le Bars et al., 1975, 1976; Yoshimura and North, 1983; Hylden and Wilcox, 1986; Willcockson et al., 1986; Craig and Serrano, 1994; Chen and Pan, 2002). However, morphine can also cause excitation of ongoing activity in some cells in the dorsal horn (Jones et al., 1990; Craig and Hunsley, 1991). Willcockson et al. (1986) showed that a minority $(\sim 25 \%)$ of nociceptive spinothalamic (STT) neurons was excited, rather than inhibited, by iontophoretic application of morphine in the monkey dorsal horn. No clear differences were detected between excited and inhibited STT neurons that might explain the dramatically differing responses to morphine. The effects of pruritogens on the neurons examined in this previous study were not determined and thus neurons could not be categorized as pruriceptive or not. We have found that a similar fraction $(\sim 30 \%)$ of primate STT neurons is pruriceptive (Davidson et al., 2012), suggesting that the STT neurons activated by morphine in the study by Willcockson et al. (1986) may well have been pruriceptive. If this conclusion is correct, it would suggest that morphine may VTT neurons to pinching. lines.

\section{Pruriceptive Neurons}
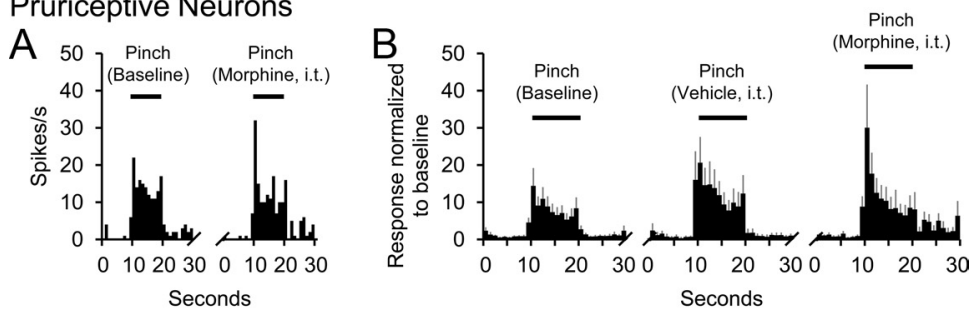

\section{Nociceptive Neurons}
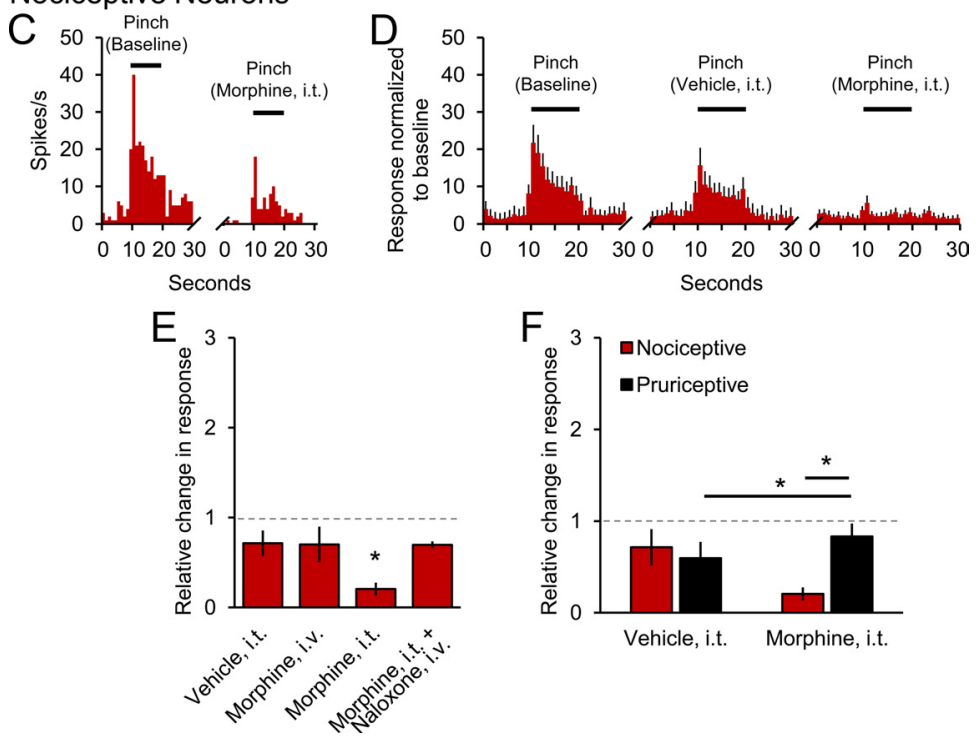

Figure 6. Differing effects of intrathecal (i.t.) application of morphine on responses to noxious pinching. $\boldsymbol{A}$, Example of a pruriceptive VTT neuron's baseline response to pinching and similar response in the presence of morphine. $\boldsymbol{B}$, Mean histograms of responses of pruriceptive cells $(n=10)$ to pinching under three conditions. C, Example of a nociceptive VTT neuron's baseline response to pinching and greatly reduced response in the presence of morphine. $\boldsymbol{D}$, Mean histogram of responses of nociceptive cells $(n=10)$ to pinching under three conditions. $\boldsymbol{E}$, Normalized mean discharge rates during pinching for nociceptive cells during four conditions. $\boldsymbol{F}$, Effects of i.t. application of vehicle and morphine on normalized mean responses of nociceptive and pruriceptive
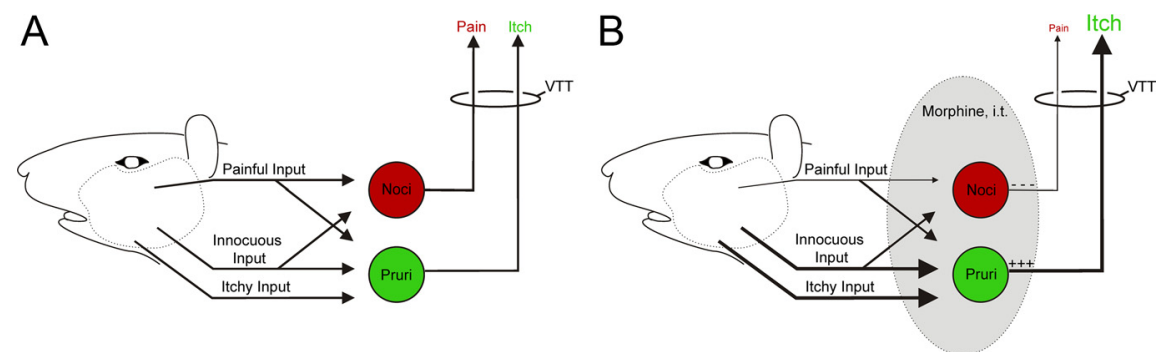

Figure 7. Schematic diagram illustrating potential changes to inputs and outputs of VTT neurons caused by intrathecal (i.t.) application of morphine. $\boldsymbol{A}$, Under normal conditions, nociceptive VTT neurons (red) receive painful and innocuous input while pruriceptive VTT neurons (green) receive painful, innocuous, and itchy input. $\boldsymbol{B}$, During i.t. application of morphine, painful input is decreased to nociceptive VTT neurons and innocuous and itchy input is increased to pruriceptive neurons, resulting in reduced pain and increased itch sensations. Although inputs are denoted with a single arrow, these inputs could be either monosynaptic or polysynaptic. Changes in relative strength of inputs and outputs in presence of morphine are indicated by changes in thickness of

activate pruriceptive and inhibit nociceptive STT neurons in primates as it does VTT neurons in rats.

Morphine has been implicated in the excitation of pruriceptive spinal neurons via activation of the opioid receptor subtype MOR1D. Upon activation by morphine, MOR1D has been shown to create a heterodimer with the gastrin-releasing peptide receptor (GRPR), leading to phospholipase C/inositol 1,4,5trisphosphate-mediated increase in intracellular calcium in het- 
erologous cells (Liu et al., 2011). GRPR-knock-out mice as well as mice in which GRPR-containing neurons have been ablated exhibit reduced scratching in response to several pruritogens, without exhibiting behavioral abnormalities in pain assays (Sun and Chen, 2007; Sun et al., 2009). Therefore, spinal neurons that contain GRPR likely play a major role in the production of itch, and may produce opioid-induced pruritus via activation of MOR1D by morphine. However, the presence of MOR1D in the rat spinal cord has been questioned (Oldfield et al., 2008), and it is as yet unknown whether spinal projection neurons or interneurons, or both, contain GRPR. The current data do not necessarily implicate the involvement of excitatory $\mu$-opioid receptors; excitation of pruriceptive VTT neurons by morphine could also be a consequence of disinhibition via activation of inhibitory $\mu$-opioid receptors on inhibitory interneurons.

In addition to causing itch, morphine has been implicated in the production of hyperknesis and alloknesis. In humans, itch produced by intradermal injection of histamine was significantly increased by coadministration of morphine as well as $\beta$-endorphin or the methionine-enkephalin analog FK 33-824 (Fjellner and Hägermark, 1982). Similarly in rats, morphine increased the amount of scratching caused by intradermal injection of chloroquine (Onigbogi et al., 2000). In addition, intrathecal application of morphine increased responses to injection of histamine into the skin by dorsal horn neurons for which axonal projections had not been determined in rats (Jinks and Carstens, 2000). In our study, morphine increased responses of pruriceptive VTT neurons to intradermal injection of serotonin in the face of the rat, possibly a contributing mechanism for hyperknesis. To our knowledge, the role of intrathecal application of morphine in alloknesis has not been experimentally addressed. The endogenous opioid system likely plays a role in the production of alloknesis, since the opioid receptor antagonist naltrexone can block experimentally induced alloknesis (Heyer et al., 2002). We show that morphine may contribute to alloknesis by greatly increasing the excitability of pruriceptive VTT neurons to innocuous mechanical stimuli.

Although responses to pinch were greatly reduced in nociceptive VTT neurons by intrathecal application of morphine, such responses were unaffected in pruriceptive VTT neurons. This result might suggest that responses in pruriceptive VTT neurons to noxious stimuli could contribute to any remaining pain sensation present after intrathecal morphine administration. Alternatively, it could suggest that responses to noxious stimuli in pruriceptive VTT neurons do not contribute to nociception. A similar conclusion has been reached recently regarding the responses to noxious stimuli of pruriceptive mouse MrgprA3 receptor-containing dorsal root ganglion neurons (Han et al., 2012). Thus, our results and those of Han et al. (2012) suggest the existence of peripheral and spinal projection neurons that, although responsive to nociceptive and pruriceptive stimuli, only contribute to itch.

In human patients, intrathecal delivery of morphine for pain relief is most often administered caudal to the spinal cord, at the level of the lumbar vertebrae. Following intrathecal application of morphine at this level, patients experience itch (often on the face) 1-3 h after intrathecal injection (Szarvas et al., 2003). This corresponds to the time period in which drugs reach peak concentrations in CSF at the level of the rostral cervical spinal cord following intrathecal delivery at lumber vertebral levels (Reiselbach et al., 1962; Max et al., 1985; Payne and Inturrisi, 1985), suggesting that the latency of pruritus following intrathecal lumbar injection of morphine may depend on the time course of rostral spread of the drug. In rodent studies, scratching in- duced by intrathecal application of morphine is reported to occur with a shorter latency. In mice, intrathecal application of morphine at the lumbar vertebral level produces an increase in scratching within $5 \mathrm{~min}$ of injection, which peaks at $10 \mathrm{~min}$ postinjection (Liu et al., 2011). Thomas and Hammond (1995) observed that facial scratching begins to increase within $10 \mathrm{~min}$, reaching a statistically significant level $20 \mathrm{~min}$ after microinjection of morphine into the rat medullary dorsal horn. Likewise, Lee et al. (2003) reported that intracisternal application of morphine in rats causes significantly increased scratching $20 \mathrm{~min}$ after administration; scratching at earlier time points was not reported. Frenk et al. (1984) observed vigorous scratch-like behaviors within $1.9 \pm 0.9 \mathrm{~min}$ of intrathecal application of morphine in rats. In the present study, morphine increased ongoing activity in pruriceptive VTT neurons $\sim 2$ min following intrathecal application (Fig. 3A). Therefore, the results of the previous behavioral studies in rodents correspond reasonably well to the results reported here.

It has been suggested that morphine may also produce itch by actions in the peripheral nervous system. There is evidence that morphine can activate receptors on mast cells in the skin, causing the release of histamine (Hermens et al., 1985). However, opioidinduced itch is generally not treatable with antihistamines and can be produced by opioid drugs, such as the selective $\mu$-opioid receptor agonist fentanyl, which does not cause histamine release (Kjellberg and Tramér, 2001; Szarvas et al., 2003). Clinically, itch as a side effect is much more common following spinal versus systemic application of morphine (Ganesh and Maxwell, 2007). In primates, scratching induced by intrathecal application of morphine is blocked by systemic administration of $\mu$-opioid receptor antagonists, but not by forms of antagonists that do not readily cross the blood-brain barrier (Thomas et al., 1993; Ko et al., 2004). We found that morphine excites pruriceptive VTT neurons only during intrathecal application; the same amount of morphine delivered systemically had no effect. Together, these results strongly suggest that pruritus induced by intrathecal application of morphine is mediated by actions at $\mu$-opioid receptors in the CNS.

There are several potential mechanism(s) underlying morphine's ability to simultaneously inhibit and excite functionally different populations of VTT neurons. Intrathecally applied morphine could conceivably act on opioid receptors located either directly on VTT neurons, or on primary afferent terminals and/or spinal interneurons that provide input to VTT neurons. If the opioid receptors underlying morphine's inhibitory effects on nociceptive cells were located on the cell bodies or dendrites of VTT neurons, we would expect responses to all inputs to be decreased. If the same were true for pruriceptive cells, then we would expect responses to all inputs to be increased. The presence of input-specific effects on responses of both types of neurons suggests that morphine is not likely generating postsynaptic excitatory or inhibitory effects in VTT neurons. It appears more likely that morphine exerts its effects by activating receptors on primary afferent terminals or spinal interneurons, leading to indirect effects in VTT neurons. Identification of the excitatory or inhibitory opioid receptor subtypes and cellular circuitry involved in morphine's distinctly different effects on pruriceptive versus nociceptive VTT neurons remains an important area for future research and the development of better treatment options for both itch and pain. The rat VTT appears to be a promising system for such studies. 


\section{References}

Ballantyne JC, Loach AB, Carr DB (1988) Itching after epidural and spinal opiates. Pain 33:149-160. CrossRef Medline

Baraka A, Noueihid R, Hajj S (1981) Intrathecal injection of morphine for obstetric analgesia. Anesthesiology 54:136-140. CrossRef Medline

Baraka A, Maktabi M, Noueihid R (1982) Epidural meperidine-bupivacaine for obstetric analgesia. Anesth Analg 61:652-656. Medline

Berendsen HH, Broekkamp CL (1991) A peripheral 5-HT1D-like receptor involved in serotonergic induced hindlimb scratching in rats. Eur J Pharmacol 194:201-208. CrossRef Medline

Bromage PR, Camporesi EM, Durant PA, Nielsen CH (1982) Nonrespiratory side effects of epidural morphine. Anesth Analg 61:490-495. Medline

Burstein R, Dado RJ, Cliffer KD, Giesler GJ Jr (1991) Physiological characterization of spinohypothalamic tract neurons in the lumbar enlargement of rats. J Neurophysiol 66:261-284. Medline

Chen SR, Pan HL (2002) Hypersensitivity of spinothalamic tract neurons associated with diabetic neuropathic pain in rats. J Neurophysiol 87: 2726-2733. Medline

Collier CB (1981) Epidural morphine. Anaesthesia 36:67. CrossRef Medline

Craig AD, Hunsley SJ (1991) Morphine enhances the activity of thermoreceptive cold-specific lamina I spinothalamic neurons in the cat. Brain Res 558:93-97. CrossRef Medline

Craig AD, Serrano LP (1994) Effects of systemic morphine on lamina I spinothalamic tract neurons in the cat. Brain Res 636:233-244. CrossRef Medline

Dado RJ, Katter JT, Giesler GJ Jr (1994) Spinothalamic and spinohypothalamic tract neurons in the cervical enlargement of rats. I. Locations of antidromically identified axons in the thalamus and hypothalamus. J Neurophysiol 71:959-980. Medline

Davidson S, Zhang X, Khasabov SG, Moser HR, Honda CN, Simone DA, Giesler GJ Jr (2012) Pruriceptive spinothalamic tract neurons: physiological properties and projection targets in the primate. J Neurophysiol 108:1711-1723. CrossRef Medline

Fjellner B, Hägermark O (1982) Potentiation of histamine-induced itch and flare responses in human skin by the enkephalin analogue FK 33-824, $\beta$-endorphin and morphine. Arch Derm Res 274:29-37. CrossRef Medline

Frenk H, Watkins LR, Mayer DJ (1984) Differential behavioral effects induced by intrathecal microinjection of opiates: comparison of convulsive and cataleptic effects produced by morphine, methadone, and d-ala ${ }^{2}$ methionine-enkephalinamide. Brain Res 299:31-42. CrossRef Medline

Ganesh A, Maxwell LG (2007) Pathophysiology and management of opioid-induced pruritus. Drugs 67:2323-2333. CrossRef Medline

Han L, Ma C, Liu Q, Weng HJ, Cui Y, Tang Z, Kim Y, Nie H, Qu L, Patel KN, Li Z, McNeil B, He S, Guan Y, Xiao B, Lamotte RH, Dong X (2012) A subpopulation of nociceptors specifically linked to itch. Nat Neurosci 16:174-182. CrossRef Medline

Henry JL (1979) Naloxone excites nociceptive units in the lumbar dorsal horn of the spinal cat. Neuroscience 4:1485-1491. CrossRef Medline

Hermens JM, Ebertz JM, Hanifin JM, Hirshman CA (1985) Comparison of histamine release in human skin mast cells induced by morphine, fentanyl, and oxymorphone. Anesthesiology 62:124-129. CrossRef Medline

Heyer G, Groene D, Martus P (2002) Efficacy of naltrexone on acetylcholine-induced alloknesis in atopic eczema. Exp Dermatol 11: 448-455. CrossRef Medline

Hosogi M, Schmelz M, Miyachi Y, Ikoma A (2006) Bradykinin is a potent pruritogen in atopic dermatitis: a switch from pain to itch. Pain 126:16-23. CrossRef Medline

Hylden JL, Wilcox GL (1986) Antinociceptive effect of morphine on rat spinothalamic tract and other dorsal horn neurons. Neuroscience 19: 393-401. CrossRef Medline

Jinks SL, Carstens E (2000) Superficial dorsal horn neurons identified by intracutaneous histamine: chemonociceptive responses and modulation by morphine. J Neurophysiol 84:616-627. Medline

Jones SL, Sedivec MJ, Light AR (1990) Effects of iontophoresed opioids on physiologically characterized laminae I and II dorsal horn neurons in the cat spinal cord. Brain Res 532:160-174. CrossRef Medline

Kitahata LM, Kosaka Y, Taub A, Bonikos K, Hoffert M (1974) Laminaspecific suppression of dorsal-horn unit activity by morphine sulfate. Anesthesiology 41:39-48. CrossRef Medline

Kjellberg F, Tramèr MR (2001) Pharmacological control of opioid-induced pruritus: a quantitative systematic review of randomized trials. Eur J Anaesthesiol 18:346-357. CrossRef Medline

Klein A, Carstens MI, Carstens E (2011) Facial injections of pruritogens or algogens elicit distinct behavior responses in rats and excite overlapping populations of primary sensory and trigeminal subnucleus caudalis neurons. J Neurophysiol 106:1078-1088. CrossRef Medline

Ko MC, Song MS, Edwards T, Lee H, Naughton NN (2004) The role of central $\mu$ opioid receptors in opioid-induced itch in primates. J Pharmacol Exp Ther 310:169-176. CrossRef Medline

Koenigstein H (1948) Experimental study of itch stimuli in animals. Arch Derm Syphilol 57:828-849. CrossRef Medline

Le Bars D, Menétrey D, Conseiller C, Besson JM (1975) Depressive effects of morphine upon lamina $\mathrm{V}$ cells activities in the dorsal horn of the spinal cat. Brain Res 98:261-277. CrossRef Medline

LeBars D, Menetrey D, Besson JM (1976) Effects of morphine upon the lamina $\mathrm{V}$ type cells activities in the dorsal horn of the decerebrate cat. Brain Res 113:293-310. CrossRef Medline

Lee H, Naughton NN, Woods JH, Ko MC (2003) Characterization of scratching responses in rats following centrally administered morphine or bombesin. Behav Pharmacol 14:501-508. CrossRef Medline

Liu XY, Liu ZC, Sun YG, Ross M, Kim S, Tsai FF, Li QF, Jeffry J, Kim JY, Loh HH, Chen ZF (2011) Unidirectional cross-activation of GRPR by MOR1D uncouples itch and analgesia induced by opioids. Cell 147:447458. CrossRef Medline

Lombard M-C, Besson J-M (1989) Electrophysiological evidence for a tonic activity of the spinal cord intrinsic opioid systems in a chronic pain model Brain Res 477:48-56.

Lundeberg L, Sundström E, Nordlind K, Verhofstad A, Johansson O (1999) Serotonin in human allergic contact dermatitis. Ann N Y Acad Sci 885: 422-426. Medline

Max MB, Inturrisi CE, Kaiko RF, Grabinski PY, Li CH, Foley KM (1985) Epidural and intrathecal opiates: cerebrospinal fluid and plasma profiles in patients with chronic cancer pain. Clin Pharmacol Ther 38: 631-641. CrossRef Medline

Moser HR, Giesler GJ Jr (2011) Pruritic responses in rat trigeminothalamic tract neurons: evidence against an itch-specific pathway. Acta Derm Venereol 91:638.

Oldfield S, Braksator E, Rodriguez-Martin I, Bailey CP, Donaldson LF, Henderson G, Kelly E (2008) C-terminal splice variants of the $\mu$-opioid receptor: existence, distribution and functional characteristics. J Neurochem 104:937945. CrossRef Medline

Onigbogi O, Ajayi AA, Ukponmwan OE (2000) Mechanisms of chloroquineinduced body-scratching behavior in rats: evidence of involvement of endogenous opioid peptides. Pharmacol Biochem Behav 65:333-337. CrossRef Medline

Paxinos G, Watson C (1982) The rat brain in stereotaxic coordinates. San Diego, CA: Academic.

Payne R, Inturrisi CE (1985) CSF distribution of morphine, methadone and sucrose after intrathecal injection. Life Sci 37:1137-1144. CrossRef Medline

Phan NQ, Bernhard JD, Luger TA, Ständer S (2010) Antipruritic treatment with systemic $\mu$-opioid receptor antagonists: a review. J Am Acad Dermatol 63:680-688. CrossRef Medline

Rasul A, Nordlund K, Wahlgren C-F (2012) Pruritic and vascular responses induced by serotonin in patients with atopic dermatitis and in healthy controls. Acta Derm Venereol. Advance online publication. Retrieved Nov. 26, 2012. doi:10.2340/00015555-1473. CrossRef Medline

Reiselbach RE, Di Chiro G, Freireich EJ, Rall DP (1962) Subarachnoid distribution of drugs after lumbar injection. N Engl J Med 267:1273-1278. CrossRef Medline

Sato M, Nakamura N, Takagi H (1971) Effect of morphine on bradykinininduced unitary discharges in the spinal cord of the rabbit. Eur J Pharmacol 16:245-247. CrossRef Medline

Scott PV, Bowen FE, Cartwright P, Mohan Rao BC, Deeley D, Wotherspoon HG, Sumrein IM (1980) Intrathecal morphine as sole analgesic during labour. Br Med J 281:351-353. CrossRef Medline

Shimada SG, LaMotte RH (2008) Behavioral differentiation between itch and pain in mouse. Pain 139:681-687. CrossRef Medline

Soga F, Katoh N, Inoue T, Kishimoto S (2007) Serotonin activates human monocytes and prevents apoptosis. J Invest Dermatol 127:1947-1955. CrossRef Medline

Spradley JM, Davoodi A, Carstens MI, Carstens E (2012) Opioid modula- 
tion of facial itch- and pain-related responses and grooming behavior in rats. Acta Derm Venereol 92:515-520. CrossRef Medline

Sun YG, Chen ZF (2007) A gastrin-releasing peptide receptor mediates the itch sensation in the spinal cord. Nature 448:700-703. CrossRef Medline

Sun YG, Zhao ZQ, Meng XL, Yin J, Liu XY, Chen ZF (2009) Cellular basis of itch sensation. Science 325:1531-1534. CrossRef Medline

Szarvas S, Harmon D, Murphy D (2003) Neuraxial opioid-induced pruritus: a review. J Clin Anesth 15:234-239. CrossRef Medline

Thomas DA, Hammond DL (1995) Microinjection of morphine into the rat medullary dorsal horn produces a dose-dependent increase in facial scratching. Brain Res 695:267-270. CrossRef Medline

Thomas DA, Williams GM, Iwata K, Kenshalo DR Jr, Dubner R (1993) The medullary dorsal horn: a site of action of morphine in producing facial scratching in monkeys. Anesthesiology 79:548-554. CrossRef Medline

Thomsen JS, Petersen MB, Benfeldt E, Jensen SB, Serup J (2001) Scratch induction in the rat by intradermal serotonin: a model for pruritus. Acta Derm Venereol 81:250-254. CrossRef Medline
Thomsen JS, Sonne M, Benfeldt E, Jensen SB, Serup J, Menné T (2002) Experimental itch in sodium lauryl sulphate-inflamed and normal skin in humans: a randomized, double-blind, placebo-controlled study of histamine and other inducers of itch. Br J Dermatol 146:792-800. CrossRef Medline

Weisshaar E, Ziethen B, Gollnick H (1997) Can a serotonin type 3 (5-HT3) receptor antagonist reduce experimentally-induced itch? Inflamm Res 46:412-416. CrossRef Medline

Willcockson WS, Kim J, Shin HK, Chung JM, Willis WD (1986) Actions of opioids on primate spinothalamic tract neurons. J Neurosci 6:2509-2520. Medline

Wilson SR, Gerhold KA, Bifolck-Fisher A, Liu Q, Patel KN, Dong X, Bautista DM (2011) TRPA1 is required for histamine-independent, Mas-related G protein-coupled receptor-mediated itch. Nat Neurosci 14:595-602. CrossRef Medline

Yoshimura M, North RA (1983) Substantia gelatinosa neurons hyperpolarized in vitro by enkephalin. Nature 305:529-530. CrossRef Medline 